\title{
UM ESTILO ENTRE MAQUIAVEL E KANT (NOTA SOBRE BOBBIO)*
}

DANILO ZOLO

1. A partir de 1974 empreendi com Norberto Bobbio uma intensa correspondência que só esmaeceu nestes últimos anos. Nosso relacionamento iniciou-se quando Bobbio respondeu a uma breve mensagem minha com uma longa carta: era uma cuidadosa análise crítica de um livro meu dedicado à teoria marxista do Estado. Essa generosa e ao mesmo tempo severa atenção com o meu trabalho me envaideceu e intensificou a minha admiração. Daquele momento em diante não me desvencilhei mais desses sentimentos em relação a Bobbio. Na verdade, com o tempo, eles se aprofundaram, mesmo quando me vi discordando de algumas de suas posições políticas.

No curso de trinta anos trocamos dezenas de mensagens onde discutíamos, principalmente, as teses sustentadas por Bobbio em seus livros e ensaios. No cerne de nossas correspondências estavam questões como a democracia, a ordem internacional, a paz e a guerra. Algumas vezes falávamos, também, sobre os temas de meus livros, especialmente Cosmopolis. Na dedicatória que me fez em um de seus livros, Bobbio se autodefiniu "cosmopolita impenitente" e, assim, não compartilhava de minhas teses antiuniversalistas, mas julgava útil discuti-las comigo. Em alguns casos, sobretudo à ocasião da guerra do Golfo e das guerras seguintes, nossa troca de cartas tornou-se verdadeira discussão pública e, às vezes, fortemente crítica.

\footnotetext{
* Este testemunho direto da presença de Norberto Bobbio no debate acadêmico e político italiano da atualidade, feito por uma figura de destaque na análise política italiana contemporânea (veja-se, por exemplo, Democracy and Complexity-a Realist Approach. Pennsylvania University Press, 1992) é de outubro de 2002. Tradução de Cristina Almeyda, a quem agradecemos a cessão do texto.
} 
No início de 1998, graças ao convite de Antonio Cassese, escrevemos e publicamos no European Journal of International Law um intenso diálogo filosófico-jurídico, posteriormente traduzido em muitas línguas e que em italiano foi publicado no Reset. Um ano depois, fui eu quem propôs a Bobbio um segundo diálogo, dedicado a temas filosóficopolíticos. Bobbio aceitou a minha proposta com entusiasmo. Acertamos os pontos a serem tratados e expus toda a minha série de perguntas. Bobbio começou a escrever suas respostas, mas logo parou. Uma forte queda, o enfraquecimento físico e, por fim, a perda de sua esposa fizeram com que fosse muito penoso continuar. Quanto a mim, não ousei propor-lhe o prosseguimento do nosso trabalho e ele acabou incompleto.

2. Li Bobbio com grande atenção. Poderia dizer que estudei e assimilei todas as principais obras filosófico-políticas, desde Politica e cultura, de 1955 e Quale socialismo?, de 1976, até Il futuro della democrazia, de 1984, citando apenas algumas entre as mais importantes para mim. O que sempre apreciei em Bobbio, ainda que não tenha sido capaz de aprender com ele, foi a lição que vem de seu estilo de pensamento: sua disposição para o diálogo com o adversário, a sábia dignidade de sua linguagem, sua clareza adamantina e seu comportamento de austera independência intelectual. Sempre existiu em Bobbio uma lúcida consciência de seu papel de homem culto: o papel de mediador em nome da razão e da liberdade, empenhado em ponderar os argumentos de todas as partes de uma causa com comedimento, cautela e modéstia. Em Politica e cultura existem vários trechos que li infinitas vezes, transcrevi, citei em meus escritos e que neste momento seria capaz de recitar de cor . Replicando a Togliatti, Bobbio escreveu: "Aprendemos poucas coisas com a história, exceto quanto ao fato de que as idéias se condensam em um sistema de ortodoxia, os poderes em uma forma hierárquica e o que pode dar nova vida ao corpo social enrijecido é, tão-somente, o hálito da liberdade, que entendo seja aquela inquietação do espírito, aquela insatisfação decorrente da ordem estabelecida, aquele aborrecimento diante de todo conformismo e que requer abertura mental e energia de caráter."

E, pouco mais adiante: "Estou convencido de que, caso não tivéssemos aprendido com o marxismo a ver a história do ponto de vista dos oprimidos, ganhando uma nova e imensa perspectiva sobre o mundo humano, não teríamos sido salvos. Talvez tivéssemos procurado por proteção em uma ilha do nosso imo ou nos teríamos colocado a serviço dos velhos poderosos. Contudo, entre aqueles que não sucumbiram, apenas alguns puderam salvar uma pequena bagagem onde, antes de jogar-se ao 
mar, puderam preservar, à própria sobrevivência, os frutos mais sãos da tradição intelectual européia: a inquietação da pesquisa, o estímulo da dúvida, a vontade do diálogo, a moderação no julgar, o escrúpulo filológico, o senso da complexidade das coisas."

Por algumas décadas, Bobbio interpretou de modo exemplar esta idéia de cultura e esta austera concessão do papel do homem culto: como poucos era um intelectual atento às emergências da política, mas desta se manteve concomitante e rigorosamente separado. Bobbio foi para muitos de nós, ao longo de décadas e em razão desse comprometimento civil, um exemplo a ser seguido.

Hoje o cenário dos relacionamentos entre cultura e política está profundamente mudado. Da sociedade industrial e do Welfare State passamos para a sociedade sem trabalho, dominada pela revolução da tecnologia e da informática e pelo poder excessivo das forças econômicas que desfrutam da dimensão global dos mercados. A falência do socialismo real e a pressão da globalização colocaram em crise até as instituições representativas. A democracia parlamentar cede lugar à videocracia, a lógica da representação é subrogada pela lógica comercial da propaganda política e da "sondocracia". Nesta ordem de coisas o poder dos estados nacionais se enfraquece e afirmam-se imponentes fenômenos migratórios, decompondo-se o equilíbrio geoeconômico estabelecido no período pós-guerra. Em toda parte é iminente a ameaça de guerra.

Uma vez mais encontramo-nos diante de mudanças que não só ocultam o sentido de uma possível função pública do homem culto, mas ameaçam a sua própria integridade intelectual. Talvez devêssemos, assim como na metáfora de Bobbio, abandonar a ilha e mergulhar no mar numa tentativa de esquivar-nos das homenagens aos poderosos, que agora são e serão cada vez mais, poderosos globais. Quanto a mim, antes de mergulhar no mar, na pequena bagagem que levarei comigo, não faltarão os livros de Bobbio que há pouco referi.

3. Muitas vezes, Bobbio fez uma pesarosa autocrítica quanto ao fato de ter aberto, ao longo de sua militância intelectual, uma grande quantidade de questões teóricas: porém, isso não significa que não tenha conseguido responder parte delas.

Talvez Bobbio exagere, mas sua autocrítica não é descabida se atribuída à tensão entre seu realismo político e a concepção ética dos valores e do destino do homem. As motivações profundas que animam sua reflexão vêm ora da tradição do realismo político europeu, ora do iluminismo. Bobbio estudou com muita atenção os autores realistas, como 
Hobbes, Marx e Weber, para não falar do elitismo italiano, de Pareto até Mosca. Ao mesmo tempo sua reflexão é consentânea ao universalismo e ao racionalismo ético-jurídico de Kant e Kelsen, que são os outros dois autores aos quais dedicou muita energia.

Bobbio opõe-se energicamente contra o moralismo e a utopia política, apreciando do marxismo o relevo dado ao caráter conflitante da política e à sua insuperável particularidade moral. De outro lado, há em Bobbio uma ética humanística que o leva a julgar os fatos políticos conforme rigorosos parâmetros morais. Por exemplo, ao repelir o liberalismo à la Hayek - um autor ao qual sempre detestou sinceramente - Bobbio afirma a necessidade de estabelecer limites morais à liberdade de mercado contra a tendência a comercializar cada valor e transformá-lo em um objeto de troca. A indiferença ética do mercado é a verdadeira responsável, segundo Bobbio, pelo consumismo desenfreado. A livre concorrência entre os produtos leva à expansão de necessidades artificiais que não merecem nenhuma tutela. Faz-se necessário, então, estabelecer critérios morais precisos para que, com base neles, se possa distinguir as expectativas sociais que não merecem ser satisfeitas e reconhecidas publicamente como direitos, descartando-se aquelas que não merecem tal reconhecimento. $\mathrm{O}$ quadro ideal para essa estratégia de seleção de direitos deveria ser o projeto iluminista da emancipação do homem contra a sujeição política, os preconceitos e a ignorância.

Em uma perspectiva realista do tipo clássico, muitas vezes contestei Bobbio, pois a ação política deveria cessar de referir-se aos grandes ideais iluministas e historicistas da igualdade, da fraternidade e da emancipação humana. Deveria liberar-se da profecia messiânica e desvencilhar-se do mito aristotélico-rousseauniano da ágora. Deveria reconhecer que a falência dos grandes discursos de emancipação dos anos 90 provou não só a baixeza das paixões humanas, mas os limites funcionais da política.

Bobbio rejeitava essa alternativa tão definitiva. Sua filosofia política, para dize-lo em uma só palavra, oscilava entre Maquiavel e Kant, num grandioso e não resolvido dilema entre suas opções filosóficas e políticas. A ascendência do iluminismo introduzia no seu pensamento uma profunda instância normativa, uma inclinação para conceber os fins da política à luz de austeras expectativas de caráter ideal: a justiça, a igualdade, a paz, a emancipação humana. Nas páginas de Bobbio, não obstante seu pessimismo, a política nunca se resumia à sua mera função pragmática: a organização dos interesses, a mediação dos conflitos, a garantia da ordem e da segurança. 
Essa tensão intrínseca ao pensamento de Bobbio pode ser criticada - e foi duramente criticada - como um grave limite teórico à sua pesquisa. Minha opinião é exatamente oposta: acho que sua pesquisa foi excepcionalmente fecunda, pois contribuiu para que o seu pensamento se tornasse vivo, problemático, exploratório. 


\section{RESUMOS/ABSTRACTS}

\section{UM ESTILO ENTRE MAQUIAVEL E KANT (NOTA SOBRE BOBBIO)}

\section{DANILO ZOLO}

Uma figura de primeira linha no pensamento político italiano contemporâneo reflete sobre o peculiar modo de pensar a política de Norberto Bobbio.

Palavras-chave: Pensamento político; Bobbio; Zolo.

\section{A STYLE BETWEEN MACHIAVELLI AND KANT} (A NOTE ON BOBBIO)

A top figure in contemporary Italian political thought reflects on Norberto Bobbio's peculiar way of thinking about politics.

Keywords: Political thought; Bobbio; Zolo. 